\title{
Identification of one insertion site of IS6110 in Mycobacterium tuberculosis H37Ra and analysis of the RvD2 deletion in $M$. tuberculosis clinical isolates
}

\author{
NICOLETTA LARI, LAURA RINDI and CARLO GARZELLI
}

Dipartimento di Patologia Sperimentale, Biotecnologie Mediche, Infettivologia ed Epidemiologia, Università di Pisa, 1-56127 Pisa, Italy

\begin{abstract}
Mycobacterium tuberculosis H37Rv and the attenuated strain H37Ra were used as a model to investigate the virulence properties of $M$. tuberculosis at the genetic level. To test whether transposition of the insertion element IS6110 might be involved in the loss of virulence of strain H37Ra, the nucleotide sequence of a differential IS6110-positive restriction fragment detected in strain H37Ra, but not in strain H37Rv, was determined. The region flanking the $3^{\prime}$ end of the IS6110 element showed partial sequence homology with internal sequences of $M$. tuberculosis $\mathrm{H37Rv}$ genes $p l c A$, plcB and plcC, each one coding for phospholipase C, a well-known bacterial virulence factor. A $\mathbf{1 0 0 \%}$ homology was found between the IS6110-flanking region and an internal sequence of $M$. bovis plcD, a further phospholipase $\mathrm{C}$ gene that is truncated and partly lost in strain $\mathrm{H37Rv}$ in the so-called RvD2 deletion. This result indicates that the differential restriction fragment of strain H37Ra originally stems from the plcD gene interrupted by the insertion of the IS6110 element. The occurrence of the RvD2 deletion was then investigated in 45 clinical isolates of $M$. tuberculosis by Southern blot. The deletion was demonstrated in 15 isolates; the entire RvD2 region (including the undisrupted plcD gene) was detected in 29 isolates, whereas only one isolate showed the RvD2 region in which the plcD gene was interrupted by an IS6110 insertion. It is concluded that disruption of the plcD gene and deletion of the RvD2 region by IS6110 insertion have no consequence for the virulence of $M$. tuberculosis, although the role of phospholipase C as a virulence factor of $M$. tuberculosis remains debatable.
\end{abstract}

\section{Introduction}

The mechanisms by which Mycobacterium tuberculosis establishes progressive disease in man are not well understood, although various strategies have been developed to identify $M$. tuberculosis virulence factors [1-5]. A promising experimental model for the investigation of $M$. tuberculosis virulence factors at the gene level is represented by the virulent strain H37Rv and the attenuated mutant H37Ra, originally derived from the classical M. tuberculosis strain H37 $[6,7]$. Several studies have tried to identify the genetic basis for the attenuation of $M$. tuberculosis H37Ra but

Received 12 Jan. 2001; revised version accepted 3 April 2001.

Corresponding author: Dr C. Garzelli (e-mail: garzelli@, biomed.unipi.it). the reason(s) for the decreased virulence of $M$. tuberculosis $\mathrm{H} 37 \mathrm{Ra}$ have not been determined.

Transposition of the insertion element IS6110 is a major force in generating genome plasticity of the tubercle bacillus $[8,9]$, including strains $\mathrm{H} 37 \mathrm{Rv}$ and H37Ra. By comparing the IS6110-based fingerprints of strains $\mathrm{H} 37 \mathrm{Rv}$ and $\mathrm{H} 37 \mathrm{Ra}$, an earlier study reported that the strain H37Ra differs from strain H37Rv in a number of IS6110-positive restriction fragments, thus demonstrating that novel insertions of the IS6110 element exist in the attenuated strain H37Ra [10]. Moreover, by a combination of clone mapping, sequence analysis and comparative genomics, Brosch et al. [11] showed that IS6110 transpositions are responsible for genomic polymorphisms and deletions that generate the genomic diversity in strains $\mathrm{H} 37 \mathrm{Rv}$ and H37Ra. In these and other studies $[12,13]$, it has been hypothesised that the transpositions of IS6110 
might have involved virulence genes. Although in $M$. tuberculosis $\mathrm{H} 37 \mathrm{Rv}$ most of the insertion sequences are located in intergenic or non-coding regions and many are clustered, suggesting the existence of insertional hot-spots that prevent genes from being inactivated [14], it becomes important to identify the differential insertion sites of IS6110 in strain H37Ra to verify whether IS6110 transposition actually interrupted any reputed virulence gene.

The present study determined the nucleotide sequence flanking the 3' end of one differential IS6110-positive $P v u$ II-fragment of the attenuated strain $\mathrm{H} 37 \mathrm{Ra}$ to identify the insertion site of the IS6110 element in the chromosome. Moreover, as these experiments led to the identification of a phospholipase C-coding gene in the so-called RvD2 region as target of IS6110 insertion, this region was investigated in a number of clinical isolates.

\section{Materials and methods}

\section{Bacterial strains}

M. tuberculosis strains H37Rv and H37Ra, M. bovis P3 and $M$. bovis BCG (Pasteur strain) were from a collection maintained in this department. The 45 clinical strains were isolated from clinical specimens by the radiometric BACTEC system according to standard procedures and identified by molecular probes (Gen-Probe, San Diego, CA, USA).

\section{IS6110-based restriction fragment length polymorphism (RFLP)}

The IS6110-based RFLP assay was run as described previously [10]. Briefly, the bacterial cells from cultures on Lowenstein-Jensen medium were suspended in saline and heated at $80^{\circ} \mathrm{C}$ for $20 \mathrm{~min}$. Genomic DNA, extracted by the N-cetyl-N,N,N-trimethyl ammonium bromide method, was digested with restriction endonuclease $P v u$ II and electrophoresed on an agarose $0.8 \%$ gel. DNA fragments were blotted on to a nylon filter and hybridised by addition of a 245-bp probing sequence specific for the IS6110 insertion element. The probe, which was prepared from $M$. bovis P3 DNA by PCR with oligonucleotides INS-1 $\left({ }^{633}\right.$ CGTGAGGGC ATCGAGGTGGC $\left.{ }^{652}\right)$ and INS-2 $\left({ }^{858}\right.$ GCGTAGGCG TCGGTGACAAA $^{877}$ ) as primers, hybridises to a target sequence located to the right of the $P v u$ II site. Hybridisation was detected on autoradiographic films by the enhanced chemiluminescence gene detection system (Hyperfilm-ECL, Amersham). The RFLP patterns were scanned and fingerprints were compared by GelCompar 4.1 software (Applied Maths, Belgium).

\section{Cloning of IS6110-specific PvuII restriction fragment and sequencing procedures}

Molecular cloning techniques were performed according to standard protocols [15]. In particular, a narrow slice around the selected band of IS6110-specific Pvu II restriction fragments from $M$. tuberculosis H37Ra genomic DNA was excised and purified from the gel with the JETsorb-Gel extraction kit (Genomed). The DNA was inserted into the dephosphorylated EcoRV site of the plasmid pBluescript SK+ (Stratagene) by the T4 DNA ligase (Pharmacia Biotech) and the ligation product was used to transform Escherichia coli JM109 cells. Bacterial clones containing inserts were identified as white colonies from which the plasmid DNA was purified by standard alkaline lysis procedures. Samples of recombinant plasmid DNA were screened for the presence of IS6110 by PCR with INS-1 and INS-2 primers as described previously [10].

Sequencing of inserted DNA fragments was performed with an automated apparatus (ALFexpress DNA sequencer, Pharmacia Biotech) according to the T7 DNA polymerase method. The Bluescript T3 and T7 universal primers and the oligonucleotide TN1, designed from the IS6110 sequence $\left({ }^{1276}\right.$ TGCCTACTA CGCTCAACGCCAG ${ }^{1297}$ ), were used as sequencing primers.

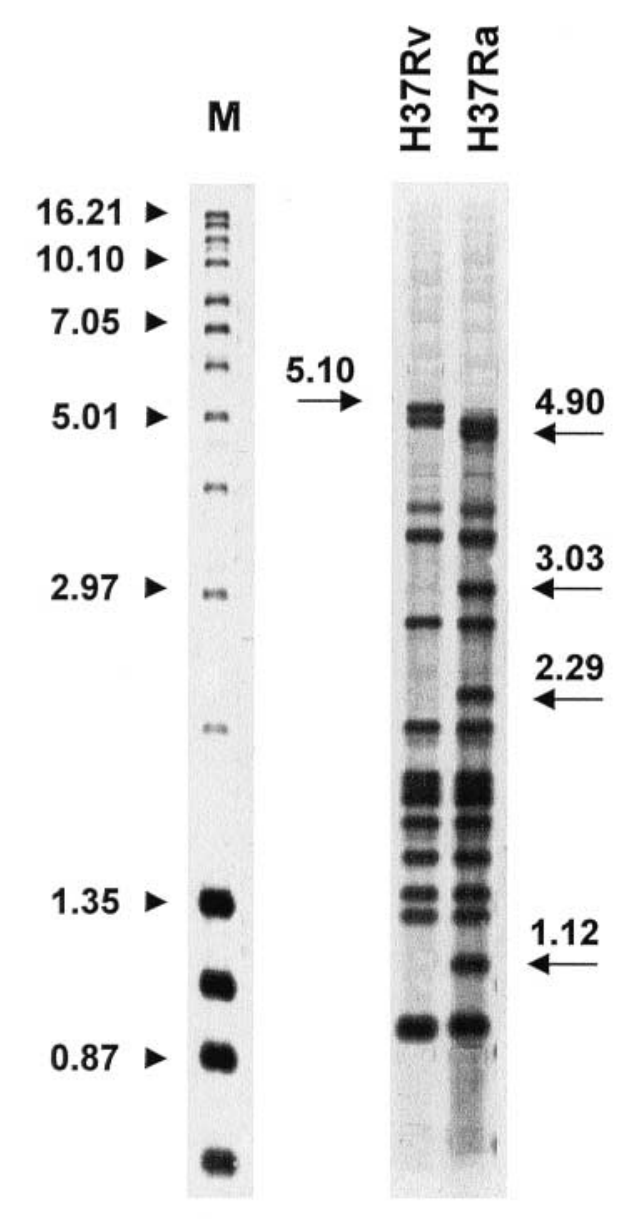

Fig. 1. IS6110-based fingerprints of M. tuberculosis strains H37Rv and H37Ra. Arrows indicate the IS6110positive restriction fragments differentially generated in the study strains (see text for more details); lane M shows the markers of molecular size expressed on the left in $\mathrm{kb}$. 


\section{Southern blot analysis of clinical isolates for RvD2 deletion}

For the analysis of clinical isolates, DNA extraction, restriction endonuclease $P v u$ II digestion, electrophoretic separation, blotting on to nylon filter and autoradiographic detection were performed as described above. Three PCR-generated, peroxidase-labelled probes, prepared from M. bovis BCG DNA, were used: a 153-bp probe, coded $a$, specific for the cloned 237-bp restriction fragment; a 277-bp probe, coded $b$, external to the $p l c D$ gene and hybridising to a sequence of the RvD2 region from position 1566 to 1842 and a 422-bp probe, coded $c$, external to the $p l c D$ gene and hybridising to a sequence of the RvD2 region from position 5383 to 5804 (nucleotide positions refer to GenBank sequence Y18606). Oligonucleotide primer pairs were: $5^{\prime}$-TCTGCGACCGCTACTTTTGCT-3' and 5'-TGATGCGCCAACCGAATCTCC-3' for probe $a$; 5'-AACCTCCAGCCGCATTTCAG-3' and 5'-CACAC GCAGTCCGCACAA-3' for probe $b$; 5'-GCCGTG CCAACCTCCTCAAA-3' and 5'-CCCCGCCGATGC TGTCAA-3' for probe c. PCR was performed in $0.5-\mathrm{ml}$ micro-centrifuge reaction tubes in a final volume of $50 \mu \mathrm{l}$ containing $10 \mathrm{mM}$ Tris- $\mathrm{HCl}(\mathrm{pH} 8.8)$, $1.5 \mathrm{mM} \mathrm{MgCl}_{2}, \quad 50 \mathrm{mM} \mathrm{KCl}$, Triton X-100 $0.1 \%$ $0.25 \mu \mathrm{M}$ primers, $200 \mu \mathrm{M}$ dNTP, Taq polymerase (Dynazyme) $0.8 \mathrm{U}$ and $M$. bovis BCG DNA $20 \mathrm{ng}$.
After an initial denaturation step of $94^{\circ} \mathrm{C}$ for $2 \mathrm{~min}$, fragment amplification was performed with a PCR Sprint Thermal cycler (Hybaid UK), set for $1 \mathrm{~min}$ at $94^{\circ} \mathrm{C}, 1 \mathrm{~min}$ at primer annealing temperatures $\left(63^{\circ} \mathrm{C}\right.$, $58^{\circ} \mathrm{C}$ and $60^{\circ} \mathrm{C}$ for probes $a, b$ and $c$, respectively), $2 \mathrm{~min}$ at $72^{\circ} \mathrm{C}$ for 30 cycles, followed by one final 4 -min extension at $72^{\circ} \mathrm{C}$. The amplicons were purified by Sephadex G-50 chromatography column, precipitated with ethanol $96 \%$, solubilised with TE buffer and covalently labelled with horseradish peroxidase (HRP) by glutaraldehyde according to the procedure of the ECL Direct System (Amersham).

\section{Results and discussion}

Fig. 1 shows the IS6110-based fingerprints of $M$. tuberculosis $\mathrm{H} 37 \mathrm{Rv}$ and H37Ra obtained by the use of the restriction endonuclease $P v u \mathrm{II}$ and an IS6110specific DNA probe homologous to a sequence located at the right of the $P v u \mathrm{II}$ site; the banding patterns seem to correspond to genotypes Rv4 and Ral of the H37Rv/ $\mathrm{Ra}$ variants recently defined by Bifani and colleagues [16]. The RFLP analysis shows one differential band of c. $5.1 \mathrm{~kb}$ in strain $\mathrm{H} 37 \mathrm{Rv}$ and four differential bands of c. $1.12,2.29,3.03$ and $4.90 \mathrm{~kb}$ in strain H37Ra. As each IS6110-positive restriction fragment includes a part of the IS6110 element, spanning from the $P v u \mathrm{II}$

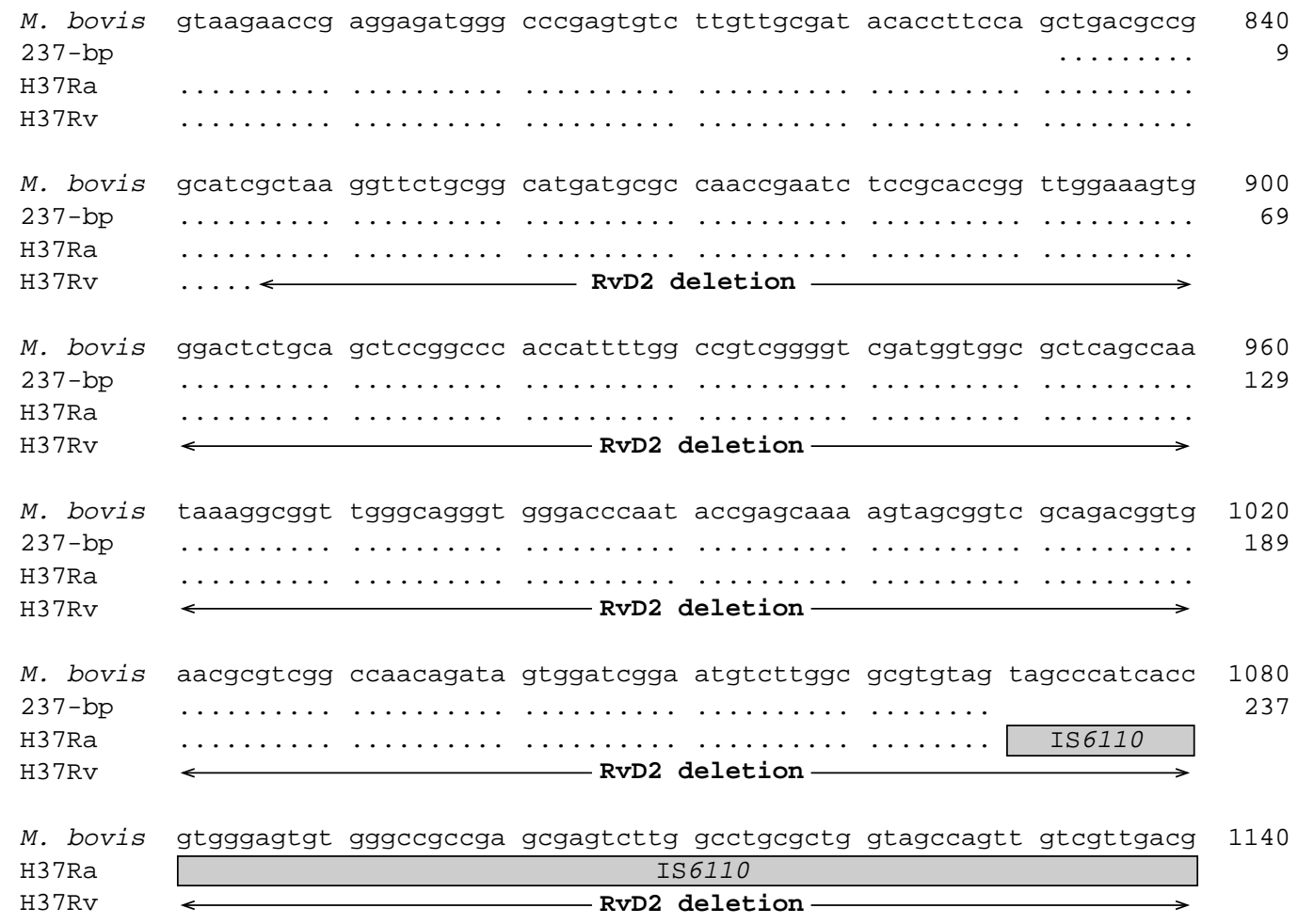

Fig. 2. Alignment of the nucleotide sequence of gene plcD of $M$. bovis BCG-Pasteur (accession no. Y18606) with the 237-bp sequence fragment flanking the $3^{\prime}$ end of IS6110 in the PvuII restriction fragment cloned from M. tuberculosis H37Ra, M. tuberculosis H37Ra (accession no. AJ242907) and M. tuberculosis H37Rv (accession no. Z95890). Only alignment from position 781 to 1140 of the 1545-bp plcD gene is shown. Dots indicate nucleotide identity; RvD2 deletion in strain H37Rv and IS6110 element in strain H37Ra are indicated by arrowhead lines and light grey boxes, respectively. 


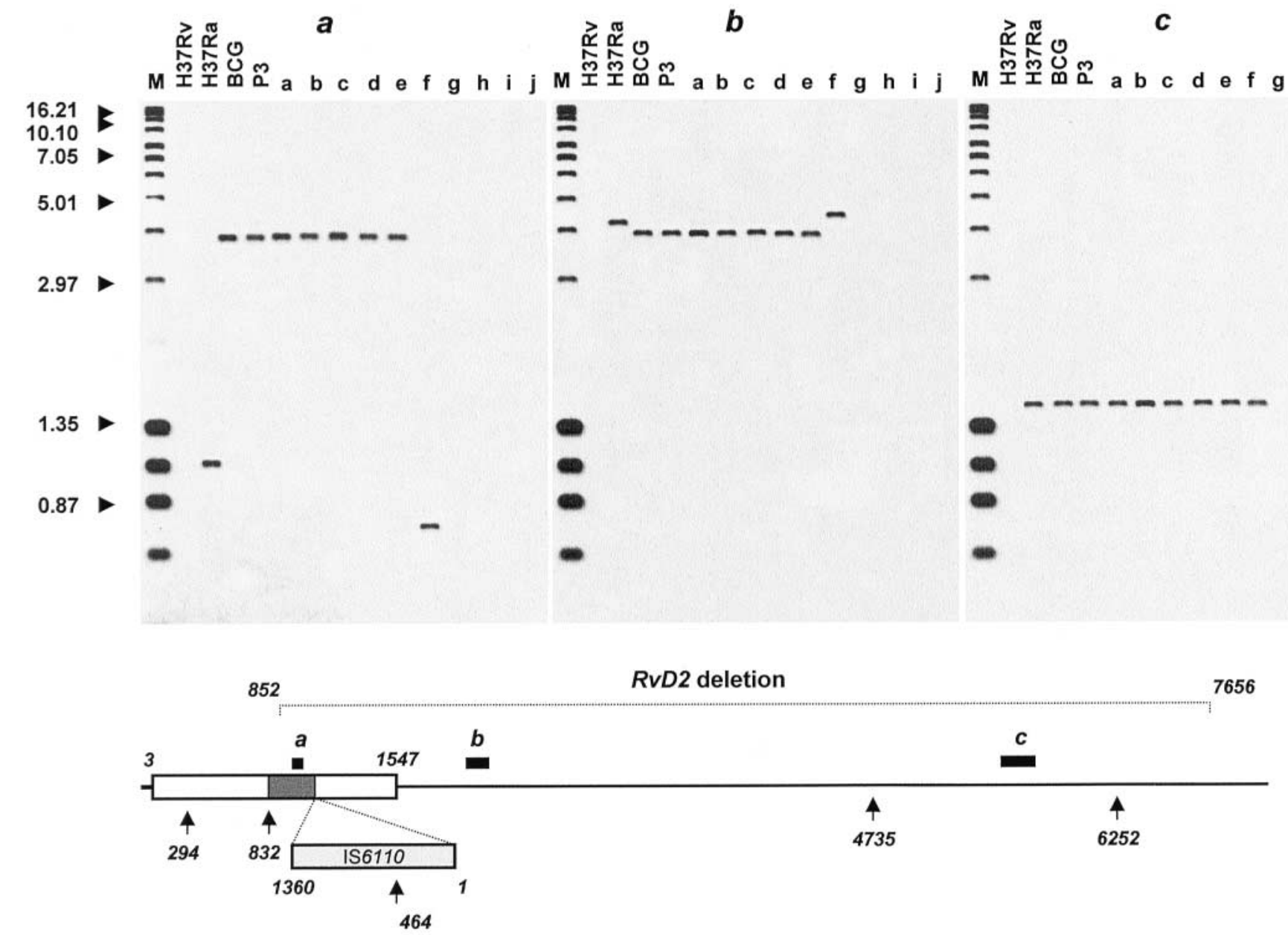

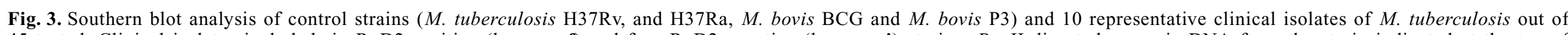

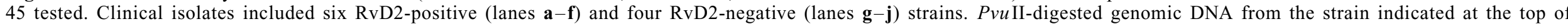
each lane was electrophoresed, blotted on to nylon filter and then hybridised with probes $a, b$ and $c$ indicated above each panel. M, mol. wt markers. The drawing at the bottom of

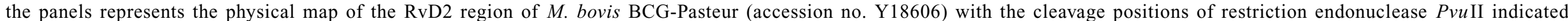

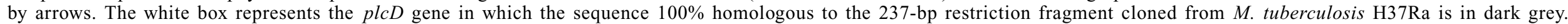

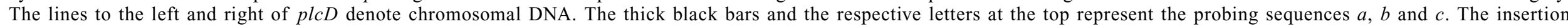

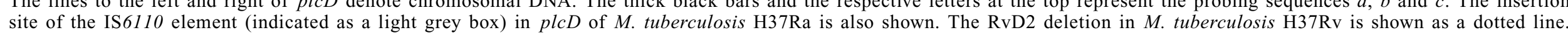




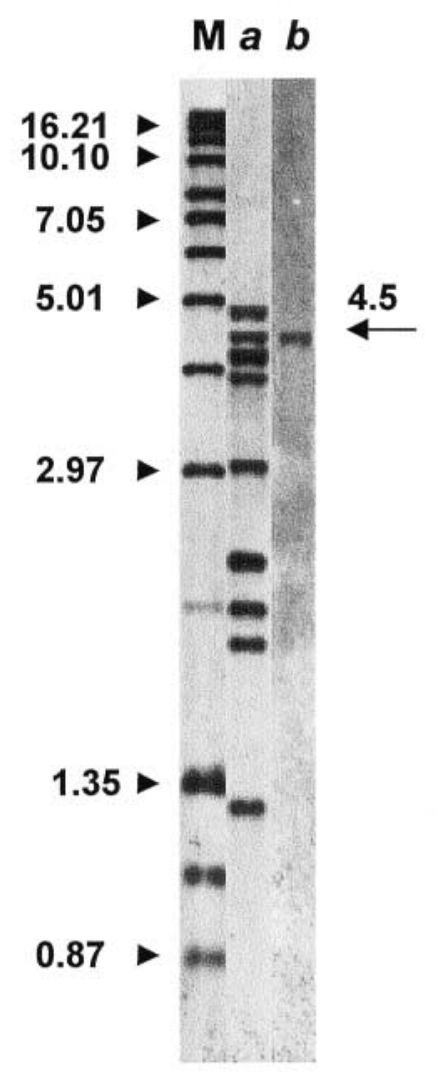

Fig. 4. Southern blot analysis of the M. tuberculosis isolate indicated as $\mathbf{f}$ in Fig. 3. Blots, prepared as described in Fig. 3, were hybridised with a IS6110specific probe (lane a) or with the RvD2-spefic probe $b$ (see legend to Fig. 3 for details) (b). The position of bands in each lane was normalised by equating external molecular size markers between the films, so that band positions of the fingerprints are mutually comparable. Banding patterns were compared with GelCompar 4.1 software by the UPGMA clustering method using the Dice coefficient, following the instructions of the GelCompar manufacturer. M, mol. wt markers.

restriction site CAG $\downarrow$ CTG located at IS position 464 to the $3^{\prime}$ terminus of the IS element at position 1360, and an unknown sequence flanking the $3^{\prime}$ end of IS6110, it becomes important to identify such a flanking sequence in the H37Ra strain to identify the insertion sites of the IS6110 element in the chromosome and verify whether IS6110 transposition actually interrupted any putative virulence gene. This paper reports the results relative to the 1.12-kb IS6110-positive, $P v u$ II restriction fragment from M. tuberculosis H37Ra.

A narrow slice around the $1.12 \mathrm{~kb}$ fragment was excised from a gel of $P v u \mathrm{II}$-digested genomic DNA and the DNA fragment was purified and cloned into the plasmid pBluescript SK+ in E. coli JM109 cells. Bacterial clones containing the specific insert were identified by screening samples of recombinant plasmid DNA for the presence of IS6110 by PCR and by restriction endonuclease analysis. Inserted DNA fragments from three positive clones were sequenced by using the Bluescript $\mathrm{T} 3$ and $\mathrm{T} 7$ universal primers and an oligonucleotide designed from the IS6110 sequence as sequencing primers. The cloned mycobacterial DNA fragment was found to consist of a 1133-bp fragment containing (i) an 896-bp sequence homologous to the IS6110 sequence from the $P v u$ II restriction site to the $3^{\prime}$ end of the IS sequence (as expected) and (ii) a 237bp sequence flanking the $3^{\prime}$ end of IS6110. When analysed in the M. tuberculosis $\mathrm{H} 37 \mathrm{Rv}$ database [14], the sequence showed partial nucleotide identity (72$78 \%$ with the genes $p l c A, p l c B$ and $p l c C$, all coding for phospholipase C (PLC), a well-known bacterial virulence factor not only for extracellular pathogens, such as Clostridium perfringens, Pseudomonas aeruginosa and Staphylococcus aureus [17-20], but also for facultative intracellular pathogens, such as Listeria monocytogenes [21,22]. On the other hand, the $M$. tuberculosis $\mathrm{H} 37 \mathrm{Rv}$ genome is known to contain a truncated open-reading frame of $840 \mathrm{bp}$ of a further $p l c$ gene, i.e., $p l c D^{\prime}$, separated from the $p l c A, B, C$ locus by c. $640 \mathrm{~kb}$ [14]. According to recent reports, $p l c D^{\prime}$ originally resulted from the insertion of IS6110 in the $p l c D$ gene [23], an event that disrupted the $p l c D$ gene and determined the deletion of a 7.9-kb fragment, known as RvD2, which also includes a sugar transferase, an oxidoreductase and a membrane protein $[11,24]$. The unbroken $p l c D$ gene, without IS6110 insertion, is present in the genome of M. bovis, including the BCG strain [24]. Therefore, this study aligned the 237-bp sequence from the cloned $P v u \mathrm{II}$ restriction fragment with the RvD2 region of $M$. bovis BCG-Pasteur (GenBank accession no. Y18606) and found $100 \%$ nucleotide homology to an internal sequence of the $p l c D$ gene, from position 832 to 1068 (Fig. 2). This indicates that the differential 1133bp restriction fragment of strain H37Ra stems from the $p l c D$ gene interrupted by the insertion of the IS6110 element, part of the gene being then lost in strain $\mathrm{H} 37 \mathrm{Rv}$ in the RvD2 deletion; as shown in Fig. 2, the last 14 bases of the truncated $p l c D^{\prime}$ of strain $\mathrm{H} 37 \mathrm{Rv}$, just before the RvD2 deletion, are also found at the end of the 237-bp fragment of strain H37Ra.

The occurrence of the RvD2 deletion was then sought in 45 clinical isolates of M. tuberculosis by Southern blot analysis. For this purpose, $P v u$ II-cleaved genomic DNA of each isolate was electrophoresed, blotted on to nylon filters and then hydridised with three probing sequences, named $a, b$ and $c$, prepared by PCR from M. bovis $\mathrm{BCG} \mathrm{DNA}$, and specific for the RvD2 region (see drawing at bottom of Fig. 3); in particular, probe $a$ hybridised to the above-described 237-bp sequence of the $p l c D$ gene in a 3903-bp $P v u$ II restriction fragment; probe $b$ hybridised to a sequence located externally to the $p l c D$ gene in the same 3903-bp restriction fragment; probe $c$ hybridised to the contiguous 1517bp $P v u$ II restriction fragment in the RvD2 region. As expected, no hybridisation signal was obtained with any 
A

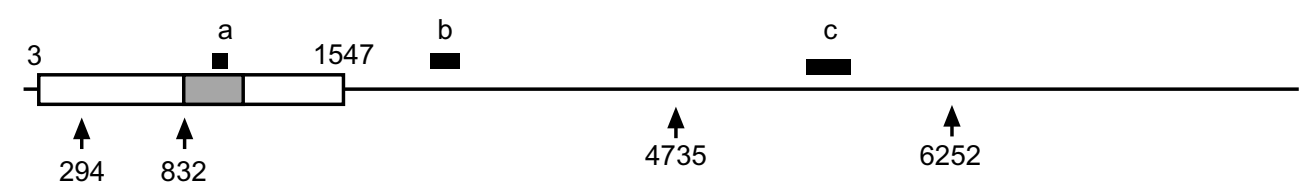

B
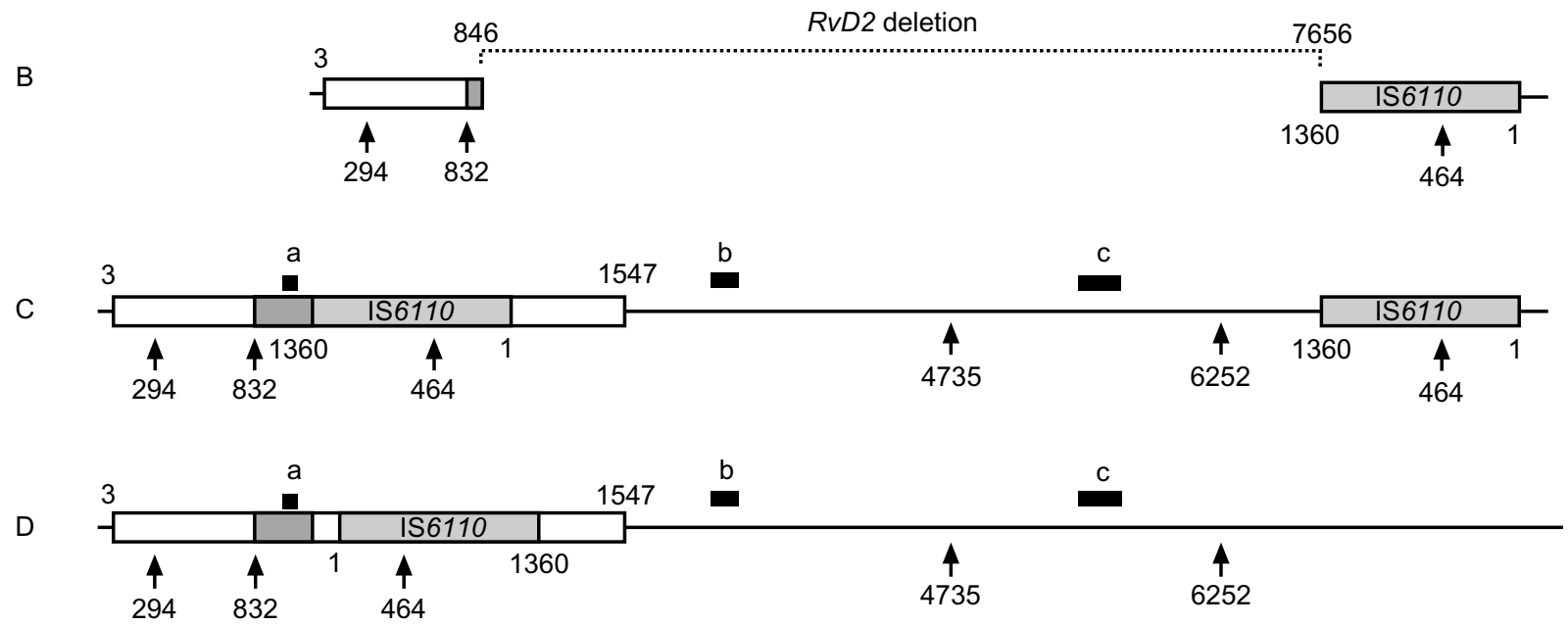

Fig. 5. Polymorphism in the RvD2 region of M. tuberculosis. Drawings represent the proposed physical map of the RvD2 region in (A) M. bovis and 29 clinical isolates; (B) M. tuberculosis H37Rv and 15 clinical isolates; (C) M. tuberculosis H37Ra; (D) clinical isolate shown in lane f of Fig. 3. Refer to legend to Fig. 3 for symbols of drawings. Distances between nucleotide positions are not to scale.

of the molecular probes in M. tuberculosis H37Rv, thus confirming the RvD2 deletion. M. tuberculosis H37Ra yielded the expected bands of $1133 \mathrm{bp}, 4131 \mathrm{bp}$ and $1517 \mathrm{bp}$ with probes $a, b$ and $c$, respectively (the 4131-bp band includes a 464-bp fragment of the IS6110 element plus a fragment of RvD2 from position 1068 - the insertion site of IS6110 - to the PvuII site at position 4735). M. bovis BCG and M. bovis P3 yielded the expected bands of 3903 bp with probes $a$ and $b$, and a band of 1517 bp with probe $c$. Fifteen $(33.3 \%)$ of the 45 clinical isolates gave negative results with all three probes, thus demonstrating the deletion of the entire $\mathrm{RvD} 2$ region, while 30 isolates $(66.7 \%)$ yielded a single band with each probing sequence. Of these, 29 isolates behaved as M. bovis, which indicates that these strains possess the complete RvD2 region, including the undisrupted $p l c D$ gene without IS6110 insertion. One isolate, shown in lane $f$ of Fig. 3, yielded a low-size (apparently $700 \mathrm{bp}$ ) restriction fragment with probe $a$ and a large-size fragment of c. $4.5 \mathrm{~kb}$ with probe $b$; as shown in Fig. 4 , the $4.5-\mathrm{kb}$ fragment of isolate $\mathrm{f}$ hybridised with the IS 6110 probe and with the RvD2-specific probe $b$. These results are compatible with the presence of an IS6110 element inserted in the $p l c D$ gene with an inverted orientation as compared with strain H37Ra. In fact, the nucleotide sequence of the $p l c D$ region of isolate $\mathrm{f}$ confirmed the inverted orientation of the IS6110 element and also showed that the IS6110 insertion site was located 29 bases downstream compared with the H37Ra strain (data not shown). The polymorphism of the RvD2 region in M. tuberculosis $\mathrm{H} 37 \mathrm{Rv}, \mathrm{H} 37 \mathrm{Ra}$ and clinical isolates is outlined in Fig. 5.
In summary, the demonstration of the IS6110 insertion in the plcD gene of strain H37Ra and isolate $\mathrm{f}$, and the occurrence of the RvD2 deletion in approximately onethird of clinical isolates further support previous observations indicating that the $p l c D$ gene is a hotspot for IS6110 insertion [11]. However, the RvD2 deletion has no consequence for the virulence of $M$. tuberculosis. Nevertheless, the role of PLC as a virulence factor of $M$. tuberculosis remains debatable. It has been proposed, in analogy with L. monocytogenes $[25,26]$, that mycobacterial PLC may disrupt the integrity of the phagolysosomal membrane with subsequent escape of the bacterium into the cytoplasm $[27,28]$. Moreover, some data suggest that PLC is associated with the most virulent mycobacterial species. In particular, M. tuberculosis, including strain $\mathrm{H} 37 \mathrm{Rv}$ and clinical isolates, possesses the three genes plcA, plcB and plcC [24]; in M. bovis and M. microti the region encompassing these genes is absent, being deleted in the so-called RvD5 deletion, but they have an undisrupted $p l c D$ gene [24]; M. africanum possesses all four plc genes [24]; DNA sequences homologous to the plc genes of $M$. tuberculosis have been reported in the pathogenic M. ulcerans [29], but not in other Mycobacterium spp, including $M$. smegmatis, $M$. avium and $M$. intracellulare. PLC enzymic activity also seems to correlate with mycobacterial virulence, as it has been reported in $M$. tuberculosis, including strains H37Rv and H37Ra, $M$. bovis, M. microti, M. ulcerans and M. marinum, but not in $M$. bovis BCG, in spite of the presence of the undisrupted $p l c D$ gene [29-31]. However, the available experimental data failed to demonstrate a direct role of 
PLC in mycobacterial virulence. Studies from this and another laboratory have shown that cloning and expression of $p l c A$ and $p l c B$ genes of $M$. tuberculosis into the non-pathogenic, fast-growing bacterium $M$. smegmatis do not confer growth advantage in macrophages or in experimental animals [32; Lari et al., unpublished results].

In conclusion, although IS6110-mediated disruption of the $p l c D$ gene apparently does not influence the virulence properties of $M$. tuberculosis, the role of PLC as a mycobacterial virulence factor remains to be clarified. Complementation experiments aimed at restoring $p l c D$ expression in the attenuated strain $M$. tuberculosis $\mathrm{H} 37 \mathrm{Ra}$ and the disruption of the plcA, $B$, $C$ locus in the virulent strain $M$. tuberculosis H37Rv will probably provide conclusive evidence.

We thank Dr Stephen V. Gordon for helpful advice. This work was supported by funds from the Italian 'Istituto Superiore di Sanità', National Research Program on AIDS, ISS grant nos. 50B.20 and 50C. 11 .

\section{References}

1. Arruda S, Bonfim G, Knights R, Huima-Byron T, Riley LW. Cloning of an $M$. tuberculosis DNA fragment associated with entry and survival inside cells. Science 1993; 261: 1454-1457.

2. Clark-Curtiss JE. Identification of virulence determinants in pathogenic mycobacteria. In: Vogt PK, Mahan MJ (eds) Bacterial infections: close encounters at the host pathogen interface. (Curr Top Microbiol Immunol vol 225). 1998: 57-79.

3. Berthet F-X, Lagranderie M, Gounon $\mathrm{P}$ et al. Attenuation of virulence by disruption of the Mycobacterium tuberculosis erp gene. Science 1998; 282: 759-762.

4. Rindi L, Lari N, Garzelli C. Search for genes potentially involved in Mycobacterium tuberculosis virulence by mRNA differential display. Biochem Biophys Res Commun 1999; 258: 94-101.

5. Graham JE, Clark-Curtiss JE. Identification of Mycobacterium tuberculosis RNAs synthesized in response to phagocytosis by human macrophages by selective capture of transcribed sequences (SCOTS). Proc Natl Acad Sci USA 1999; 96: $11554-11559$.

6. Steenken W, Oatway WH, Petroff SA. Biological studies of the tubercle bacillus. III. Dissociation and pathogenicity of the $\mathrm{R}$ and $\mathrm{S}$ variants of the human tubercle bacillus (H37). J Exp Med 1934; 60: 515-540.

7. Steenken W, Gardener LU. History of H37 strain of tubercle bacillus. Am Rev Tuberc 1946; 54: 62-66.

8. Fang Z, Doig C, Kenna DT et al. IS6110-mediated deletions of wild-type chromosomes of Mycobacterium tuberculosis. J Bacteriol 1999; 181: 1014-1020.

9. Warren RM, Sampson SL, Richardson M et al. Mapping of IS6110 flanking regions in clinical isolates of Mycobacterium tuberculosis demonstrates genome plasticity. Mol Microbiol 2000; 37: 1405-1416

10. Lari N, Rindi L, Lami C, Garzelli C. IS6110-based restriction fragment length polymorphism (RFLP) analysis of Mycobacterium tuberculosis H37Rv and H37Ra. Microb Pathog 1999; 26: $281-286$.

11. Brosch R, Philipp WJ, Stavropoulos E, Colston MJ, Cole ST, Gordon SV. Genomic analysis reveals variation between Mycobacterium tuberculosis $\mathrm{H} 37 \mathrm{Rv}$ and the attenuated $M$. tuberculosis H37Ra strain. Infect Immun 1999; 67: 5768-5774.

12. Jacobs WR, Bloom BR. Molecular genetic strategies for identifying virulence determinants of Mycobacterium tuberculosis. In: Bloom BR (ed) Tuberculosis: pathogenesis, protection, and control. Washington DC, ASM Press. 1994: 253-268.

13. Cole ST, Smith DR. Toward mapping and sequencing the genome of Mycobacterium tuberculosis. In: Bloom BR (ed) Tuberculosis: pathogenesis, protection, and control. Washington DC, ASM Press. 1994: 227-238.

14. Cole ST, Brosch R, Parkhill J et al. Deciphering the biology of Mycobacterium tuberculosis from the complete genome sequence. Nature 1998; 393: 537-544.

15. Sambrook J, Fritsch EF, Maniatis T. Molecular cloning: a laboratory manual, 2nd edn. Cold Spring Harbor, NY: Cold Spring Harbor Laboratory Press. 1989.

16. Bifani P, Moghazeh S, Shopsin B, Driscoll J, Ravikovitch A, Kreiswirth BN. Molecular characterization of Mycobacterium tuberculosis $\mathrm{H} 37 \mathrm{Rv} / \mathrm{Ra}$ variants: distinguishing the mycobacterial laboratory strain. J Clin Microbiol 2000; 38: 3200-3204.

17. Smith LDS. Virulence factors of Clostridium perfringens. Rev Infect Dis 1979; 1: 254-262.

18. Ostroff RM, Wretlind B, Vasil ML. Mutations in the hemolytic-phospholipase $\mathrm{C}$ operon result in decreased virulence of Pseudomonas aeruginosa PAO1 grown under phosphatelimiting conditions. Infect Immun 1989; 57: 1369-1373.

19. Rahme LG, Stevens EJ, Wolfort SF, Shao J, Tompkins RG, Ausubel FM. Common virulence factors for bacterial pathogenicity in plants and animals. Science 1995; 268: 1899-1902.

20. Daugherty S, Low MG. Cloning, expression, and mutagenesis of phosphatidylinositol-specific phospholipase C from Staphylococcus aureus: a potential staphylococcal virulence factor. Infect Immun 1993; 61: 5078-5089.

21. Camilli A, Goldfine H, Portnoy DA. Listeria monocytogenes mutants lacking phosphatidylinositol-specific phospholipase C are avirulent. J Exp Med 1991; 173: 751-754.

22. Raveneau J, Geoffroy C, Beretti J-L, Gaillard J-L, Alouf JE, Berche P. Reduced virulence of a Listeria monocytogenes phospholipase-deficient mutant obtained by transposon insertion into the zinc metalloprotease gene. Infect Immun 1992; 60: $916-921$.

23. Gordon SV, Heym B, Parkhill J, Barrell B, Cole ST. New insertion sequences and a novel repeated sequence in the genome of Mycobacterium tuberculosis H37Rv. Microbiology 1999; 145: 881-892.

24. Gordon SV, Brosch R, Billault A, Garnier T, Eiglmeier, Cole ST. Identification of variable regions in the genomes of the tubercle bacilli using bacterial artificial chromosome arrays. Mol Microbiol 1999; 32, 643-655.

25. Marquis H, Doshi V, Portnoy DA. The broad-range phospholipase $\mathrm{C}$ and a metalloprotease mediate listeriolysin $\mathrm{O}$ independent escape of Listeria monocytogenes from a primary vacuole in human epithelial cells. Infect Immun 1995; 63: 4531-4534.

26. Smith GA, Marquis H, Jones S, Johnston NC, Portnoy DA, Goldfine $\mathrm{H}$. The two distinct phospholipases $\mathrm{C}$ of Listeria monocytoges have overlapping roles in escape from a vacuole and cell-to-cell spread. Infect Immun 1995; 63: 4231-4237.

27. McDonough KA, Kress Y, Bloom BR. Pathogenesis of tuberculosis: interaction of Mycobacterium tuberculosis with macrophages. Infect Immun 1993; 61: 2763-2773.

28. Vera-Cabrera L, Howard ST, Laszlo A, Johnson WM. Analysis of genetic polymorphism in the phospholipase region of Mycobacterium tuberculosis. J Clin Microbiol 1997; 35: 1190-1195.

29. Gomez A, Mve-Obiang A, Vray B et al. Biochemical and genetic evidence for phospholipase C activity in Mycobacterium ulcerans. Infect Immun 2000; 68: 2995-2997.

30. Wheeler PR, Ratledge C. Control and location of acylhydrolysing activity in pathogenic mycobacteria. $J$ Gen Microbiol 1992; 138: 825-830.

31. Johansen KA, Gill RE, Vasil ML. Biochemical and molecular analysis of phospholipase C and phospholipase D activity in mycobacteria. Infect Immun 1996; 64: 3259-3266.

32. Miller BH, Shinnick TM. Evaluation of Mycobacterium tuberculosis genes involved in resistance to killing by human macrophages. Infect Immun 2000; 68: 387-390. 